\title{
Rancang Bangun Antena Bowtie pada Video Sender sebagai Pemancar TV Streaming
}

\author{
Nabila Shaffa Bestari ${ }^{1}$ dan Agus Wagyana ${ }^{2}$ \\ Teknik Elektro, Politeknik Negeri Jakarta, \\ Jl. Prof dr G.A. Siwabessy, Depok, 16424, Indonesia \\ nabila.shaffab@gmail.com ${ }^{1}$, awagyana@gmail.com ${ }^{2}$
}

\begin{abstract}
A streaming television usually broadcasted through internet and can be watched on computer or mobile phone. However it can also be seen through television using video sender as the transmitter. To transmit it, of course, a suitable antenna is needed, in this case a bowtie antenna is selected. This research describe the design of a bowtie antenna that will be used as a transmitter antenna on a video sender. This bowtie antenna is designed by using an aluminum plate works on frequency of $655 \mathrm{MHz}$ and has a return loss value of $-21.127 \mathrm{~dB}$, VSWR 1.192, $5.11 \mathrm{~dB}$ gain and bi-directional radiation pattern. The analysis process is carried out by analyzing the data taken from the audio and video results received in television as well as data from the measurement of signal strength captured by Register Transfer Level Software Define Radio (RTL SDR) and dipole antennas. Measurement results will be displayed in the sdrSharp software. The results of this measurement will be associated with field strength which is related to television signals. This bowtie antenna can transmit audio and video up to $30 \mathrm{~m}$ and has an average field strength value in Line of Sight (LOS) conditions of $120.3208 \mathrm{dB \mu V} / \mathrm{m}$ and at Non Line of Sight (NLOS) conditions of $123.5014 \mathrm{dB \mu V} / \mathrm{m}$ which is in accordance with the field strength standard in Indonesia that regulated in Perkominfo No. 31 Tahun 2014 which is above $70 \mathrm{dB \mu V} / \mathrm{m}$ in band $\mathrm{V}$.
\end{abstract}

Keywords - Bowtie antenna, field strength, SDR, sdrSharp, video sender

Abstrak- Televisi streaming pada umumnya ditonton melalui komputer atau handphone melalui internet, namun dapat juga dilihat melalui televisi dengan menggunakan video sender sebagai pemancarnya. Untuk memancarkannya tentunya diperlukan sebuah antena yang sesuai, dalam hal ini dipilih antena bowtie. Pada penelitian ini dipaparkan mengenai perancangan antena bowtie yang akan digunakan sebagai antena pemancar pada video sender. Antena bowtie yang dirancang menggunakan plat aluminium, bekerja pada frekuensi $655 \mathrm{MHz}$ memiliki nilai return loss $-21,127 \mathrm{~dB}$, VSWR 1,192, gain 5,11 dB dan pola radiasi bidirectional. Proses analisis dilakukan dengan data yang diambil dari hasil audio dan video yang diterima pada televisi serta data hasil pengukuran kekuatan sinyal yang ditangkap menggunakan Register Transfer Level Software Define Radio (RTL SDR) dan antena dipole. Pengukuran akan ditampilkan pada software sdrSharp. Hasil pengukuran ini dikaitkan dengan field strength yang merupakan pengukuran sinyal televisi. Antena bowtie ini dapat memancarkan audio dan video hingga jarak $30 \mathrm{~m}$ dan memiliki nilai rata-rata field strength pada kondisi Line of Sight (LOS) sebesar $120,3208 \mathrm{~dB} \mu \mathrm{V} / \mathrm{m}$ dan pada kondisi Non Line of Sight (NLOS) sebesar $123,5014 \mathrm{~dB} \mu \mathrm{V} / \mathrm{m}$ yang telah sesuai dengan standar field strength di Indonesia yang diatur pada Perkominfo No. 31 Tahun 2014 yaitu di atas $70 \mathrm{~dB} \mu \mathrm{V} / \mathrm{m}$ pada band $\mathrm{V}$.

Kata kunci-Antena Bowtie, field strength, SDR, sdrSharp, video sender

\section{PENDAhUluan}

Televisi streaming umumnya ditonton melalui komputer atau telepon seluler yang terhubung dengan internet. Televisi streaming ini juga dapat ditonton di televisi sehingga dapat ditonton lebih jelas dan nyaman dengan menggunakan perangkat yang bernama video sender. Video sender ini dapat digunakan untuk repeater televisi biasa [1]. Untuk dilihat melalui televisi, video dipancarkan menggunakan video sender yang terhubung dengan PC. Dari pancaran video sender, video akan diterima oleh pesawat televisi. Pancaran sinyal dari video sender ini terbatas karena daya pemancar dari video sender juga terbatas tidak seperti pemancar televisi pada umumnya.
Antena pemancar yang sesuai diperlukan agar video sender dapat memancarkan video dengan kualitas yang baik serta jangkauan yang dapat menjangkau area yang diinginkan. Antena pemancar ini harus bekerja pada frekuensi UHF agar bisa diterima oleh pesawat televisi. Untuk mendapat antena yang bekerja sesuai yang diharapkan, diperlukan perancangan antena agar mendapatkan antena yang baik dan bekerja sesuai yang diharapkan. Antena bowtie merupakan salah satu variasi dari antena dipole. Antena ini meskipun terkenal sebagai receiver dapat juga digunakan sebagai transceiver [2] selain itu bowtie dikenal memiliki bandwidth yang lebar sehingga biasa digunakan untuk frekuensi UHF [3] yang merupakan frekuensi televisi dan juga digunakan sebagai antena broadband untuk indoor [4]. 
Antena Bowtie dapat digunakan sebagai pemancar sehingga akan dilihat karakteristik antena seperti return loss, VSWR, pola radiasi dan gain, hasil pemancaran jika dibandingkan dengan antena default pada video sender serta hasil kekuatan sinyal (field strength) antena bowtie dengan jarak $30 \mathrm{~m}$ apakah sudah sesuai dengan peraturan Kominfo No. 31 Tahun 2014 [5]. Besarnya field strength dipengaruhi oleh beberapa faktor, antara lain daya pemancar, ketinggian antena pemancar dan penerima, keadaan geografis pada titik pengukuran. Sedangkan besarnya field strength yang terukur dipengaruhi oleh jarak pengukuran terhadap antena pemancar [6].

Tujuan dari penelitian ini adalah untuk membuat dan merealisasikan antena video sender yang dapat memancarkan televisi streaming ke televisi sehingga penonton dapat melihat lebih jelas dan nyaman terutama untuk siaran langsung pada suatu event.

\section{MetOde PENELITIAN}

Penelitian dilakukan di Lab Telekomunikasi Politeknik Negeri Jakarta. Channel televisi streaming yang digunakan sebagai objek penelitian adalah PSBM TV. Dari hasil penelitian ini diharapkan dapat mengetahui jarak pancar antenna bowtie pada video sender dan kualitas gambar serta kekuatan sinyal hasil pemancaran antena bowtie. Selain itu agar dapat mengetahui perbedaan kualitas gambar dan level sinyal pada keadaan Line of Sight (LOS) dan keadaan Non Line of Sight (NLOS) dengan partisi yang berbeda-beda yaitu pada partisi kaca, kayu, tembok, dan gypsum. Hasil dari pemancaran bowtie akan dibandingkan dengan antena default dari video sender.

\section{A. Perancangan Antena}

Antena Bowtie untuk video sender ini bekerja pada frekuensi $655 \mathrm{MHz}$. Untuk mengetahui dimensi antena maka dilakukan perhitungan sebagai berikut.

$$
\lambda=\frac{c}{f}=\frac{3 \times 10^{\wedge} 8}{655 \times 10^{\wedge} 6}=0,46 \mathrm{~m}=46 \mathrm{~cm}=460 \mathrm{~mm}
$$

Sehingga hasil yang didapat adalah panjang gelombang antena tersebut adalah $46 \mathrm{~cm}$. Sedangkan untuk dimensi segitiga antena dapat dihitung sebagai berikut:

$$
\begin{aligned}
& \mathrm{s}=\frac{1}{2} \lambda=\frac{1}{2} \cdot 46 \mathrm{~cm}=23 \mathrm{~cm} \\
& \mathrm{a}=\frac{1}{4} \lambda=\frac{1}{4} \cdot 46 \mathrm{~cm}=11,5 \mathrm{~cm}
\end{aligned}
$$

Keterangan:

$\mathrm{s}=$ Sisi segitiga $(\mathrm{cm})$

$\mathrm{a}=$ Alas segitiga $(\mathrm{cm})$

Rancangan dari antena bowtie yang telah disimulasikan dan dioptimasi ditampilkan pada Gambar 1. Gambar 2 menunjukkan hasil nilai return loss yaitu $-10,05 \mathrm{~dB}$ yang berarti sudah sesuai dengan standard antena yaitu $\geq-10 \mathrm{~dB}$, Gambar 3 menunjukkan hasil nilai VSWR yaitu 1,917 yang berarti masih sesuai yaitu <2, Gambar 4 menunjukkan hasil nilai Gain yaitu 4,61 dB dan Gambar 5 menunjukkan hasil simulasi pola radiasi yaitu pola radiasi bi-directional. Pola radiasi bi-directional sesuai dengan bentuk Lab Telekomunikasi yang menjadi tempat penelitian yaitu berbentuk memanjang sehingga dapat memancarkan ke semua arah.

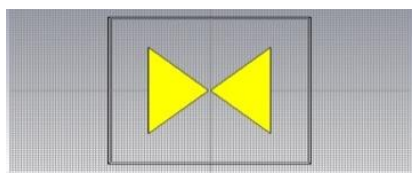

Gambar 1. Rancangan antena bowtie



Gambar 2. Hasil simulasi return loss

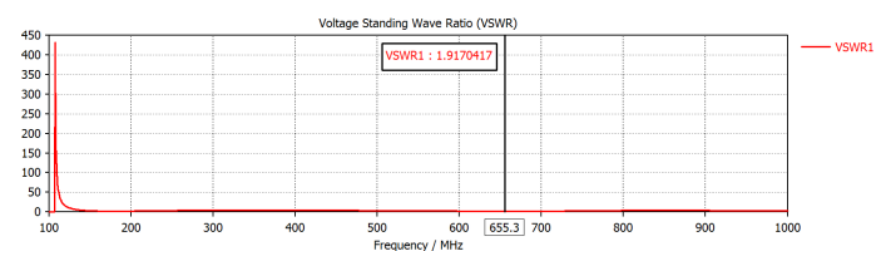

Gambar 3. Hasil simulasi VSWR
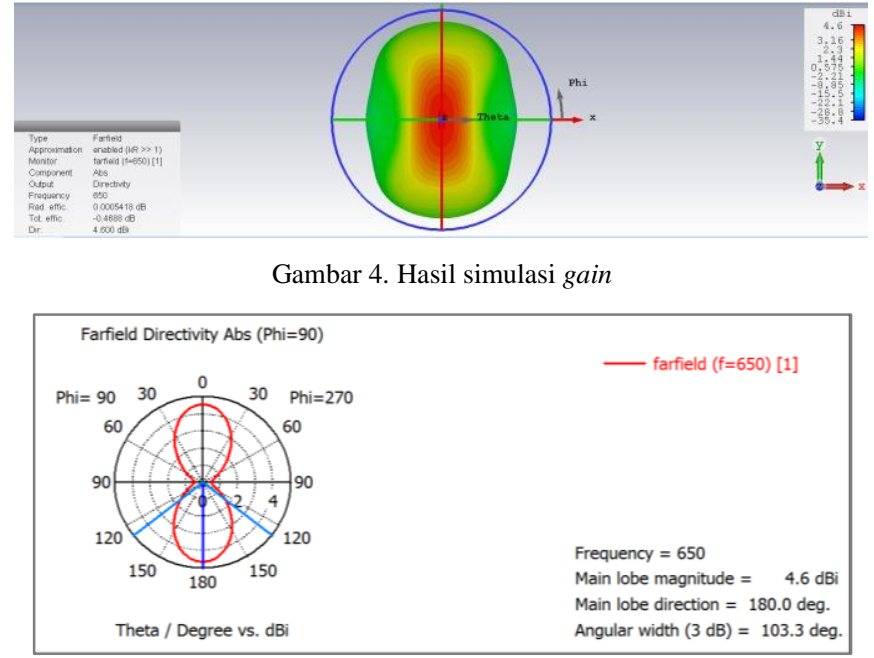

Gambar 5. Hasil simulasi pola radiasi

\section{B. Pembuatan antena}

Setelah dilakukan simulasi, dilakukan realisasi pembuatan antena. Pembuatan antena ini menggunakan plat aluminium dengan tebal $0,8 \mathrm{~cm}$ dan pipa sebagai penyangga antenanya. Gambar 6 adalah hasil pembuatan antena yang telah dilakukan.

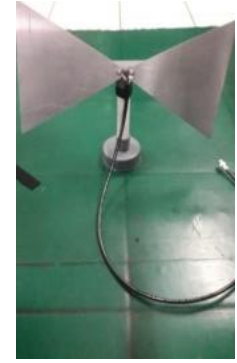

Gambar 6. Hasil pembuatan antena bowtie 


\section{Pengujian sistem}

Cara kerja sistem ditunjukkan pada Gambar 7 dan pengujian sistem mengenai performansi pemancaran kualitas gambar dan kekuatan sinyal.

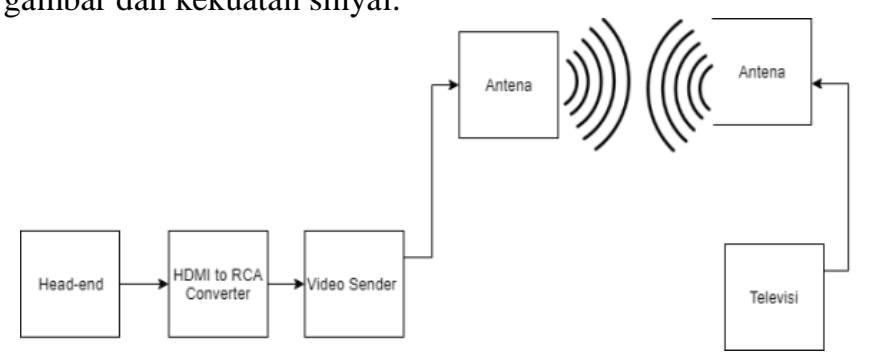

Gambar 7. Diagram blok sistem pemancar

Pengujian pemancaran dilihat dari sisi kualitas gambar dan kualitas sinyal. Pengujian terhadap kualitas gambar dilihat hasilnya pada televisi sedangkan untuk pengujian kualitas sinyal dilihat hasilnya pada laptop yang sebelumnya dihubungkan dengan dongle Software Define Radio (SDR) yang berfungsi untuk mengubah sinyal analog menjadi digital. Kedua pengujian ini dilakukan pada jarak tertentu dengan kondisi LOS pada jarak 5 sampai $30 \mathrm{~m}$ dan NLOS pada jarak $5 \mathrm{~m}, 8 \mathrm{~m}$, dan $18 \mathrm{~m}$.

\section{HASIL DAN PEMBAHASAN}

\section{A. Pengukuran Parameter Antena}

Pada bagian ini dibahas mengenai hasil pengujian parameter antena yang telah dibuat. Antena ini bekerja dengan baik pada frekuensi $655 \mathrm{MHz}$. Berikut merupakan hasil pengukuran yang telah dilakukan.

\section{1) Return Loss}

Hasil pengukuran return loss ditunjukkan pada Gambar 8 dimana nilai return loss antena bowtie ini memiliki nilai $-21,127 \mathrm{~dB}$ pada frekuensi $655 \mathrm{MHz}$ yang berarti hasil return loss ini memenuhi standar return loss antena yaitu di bawah $-10 \mathrm{~dB}$ [6]. Hasil pengukuran memiliki nilai yang lebih baik disebabkan kurang optimalnya perancangan sehingga diperbaiki pada realisasi pembuatan antena. Pengukuran dilakukan dengan menggunakan network analyzer yang dihubungkan dengan antena bowtie melalui kabel Subminiature versi A (SMA), yang kemudian hasil pengkuran dapat dibaca pada monitor.

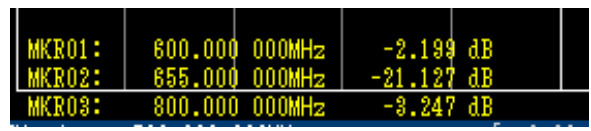

Gambar 8. Hasil return loss

\section{2) VSWR}

Hasil pengukuran VSWR yang diukur menggunakan network analyzer ditunjukkan pada Gambar 9 dimana nilai VSWR antena bowtie ini memiliki nilai 1,192 yang berarti sudah memenuhi standar yaitu nilai VSWR di bawah 2 dan mendekati 1 dan memiliki hasil yang lebih baik dibandingkan pada penelitian [6] hal ini disebabkan perbedaan bahan dasar yang digunakan yaitu pada penelitian [6] menggunakan bahan dasar zinc yang memiliki hasil 1,448.

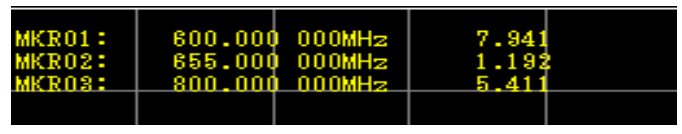

Gambar 9. Hasil VSWR

3) Pola Radiasi

Hasil pengujian pola radiasi antena bowtie ini menghasilkan bentuk pola radiasi omnidirectional, lebih spesifiknya bidirectional yang sesuai dengan pola radiasi yang dibutuhkan agar dapat memancarkan di Lab Telekomunikasi. Hasil pola radiasi ditunjukkan pada Gambar 10.

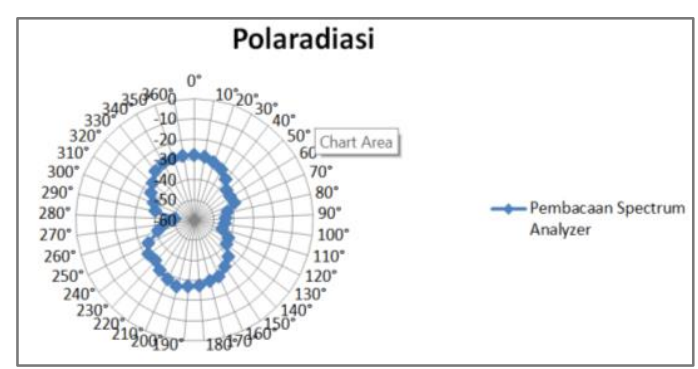

Gambar 10. Hasil pola radiasi

\section{4) Gain}

Hasil pengukuran gain didapatkan dari hasil pengukuran pola radiasi dengan hasil yang ditampilkan pada Tabel I.

TABEL I. PARAMETER GAIN

\begin{tabular}{|l|r|}
\hline Parameter & \multicolumn{1}{|c|}{ Nilai } \\
\hline P1 (rx) & $-28,22 \mathrm{~dB}$ \\
\hline P2 (tx) & $-28,11 \mathrm{~dB}$ \\
\hline Pref & $5 \mathrm{~dB}$ \\
\hline
\end{tabular}

$$
\begin{aligned}
\text { Gain } & =\mathrm{P} 1(\mathrm{rx})-\mathrm{P} 2(\mathrm{tx})+\mathrm{P}(\mathrm{ref}) \\
& =-28,22-(-28,11)+5 \\
& =5,11 \mathrm{~dB}
\end{aligned}
$$

Hasil antena bowtie yang dibuat memiliki nilai parameter yang lebih baik dengan hasil simulasi, namun masih lebih kecil dibanding hasil pada [6] yang menghasilkan gain sebesar $12 \mathrm{~dB}$. Hasil pengukuran memiliki nilai yang lebih baik disebabkan kurang optimalnya perancangan yaitu pada penempatan kedua sayap antena yang terletak terlalu jauh satu sama lain sehingga diperbaiki pada realisasi pembuatan antena.

\section{B. Pengujian Aplikasi Antena Bowtie pada Video sender}

Dari hasil pengujian aplikasi antena bowtie pada video sender didapatkan kualitas video dan audio pada televisi serta level kekuatan sinyal dari dua kondisi yaitu LOS dan NLOS. Hasil kualitas video dan audio serta kekuatan level sinyal dari antena bowtie akan dibandingkan dengan antena default dari video sender yaitu antena monopole. Selain itu pada pengujian aplikasi antena bowtie ini juga dilakukan pengukuran kuat sinyal atau field strength dengan menggunakan software sdrSharp. 


\section{1) Hasil Kualitas Gambar}

Pengujian aplikasi antena bowtie memiliki hasil yang baik. Antena ini dapat memancarkan hingga jarak $30 \mathrm{~m}$. Hasil pemancaran antena bowtie lebih baik jika dibandingkan dengan antena default-nya karena memiliki hasil gambar yang lebih sedikit noise. Banyaknya noise membuat video menjadi tidak jelas untuk dilihat. Dapat dilihat perbedaan kualitas gambar berdasarkan jarak dari Gambar 11 dengan Gambar 12. Pada Gambar 11 yaitu pada keadaan LOS di jarak $5 \mathrm{~m}$, hasil gambar jernih tanpa noise dengan level sinyal 137,42 $\mathrm{dBmV} / \mathrm{m}$. Sedangkan pada Gambar 12 yaitu pada keadaan LOS jarak $30 \mathrm{~m}$, hasil gambar memiliki banyak noise dengan level sinyal 106,228 dBmV/m.Sehingga semakin jauh jaraknya semakin besar pula noise yang masuk dari hasil pemancaran kedua antena walaupun antena bowtie memiliki hasil yang lebih sedikit noise. Sehingga pada kondisi LOS antena bowtie memiliki hasil yang lebih baik dibanding antena default.

Sedangkan pada kondisi NLOS, pada pemancaran menggunakan antena default terdapat noise di gambar yang cukup banyak sehingga membuat gambar kurang jelas, pada pemancaran menggunakan antena bowtie gambar juga memiliki noise namun terlihat lebih jelas. Perbedaan jarak dan ruangan juga mempengaruhi sinyal yang datang, semakin jauh jarak semakin banyak noise dan partisi ruangan seperti gypsum, kaca dan kayu juga mempengaruhi. Gambar 13 merupakan hasil gambar dari ruangan yang partisi antara pemancar dan penerimanya adalah gypsum dan kaca memiliki hasil yang masih jernih karena jaraknya dekat dengan level sinyal 127,52 dBmV/m. Gambar 14 merupakan hasil gambar dari ruangan yang partisinya gypsum, kayu dan kaca memiliki noise yang lebih banyak dibandingkan dengan hasil sebelumnya dengan level sinyal 124,92 dBmV/m.

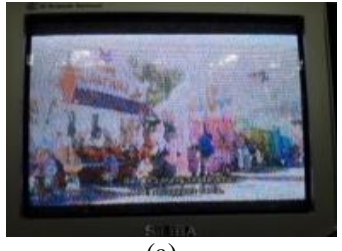

(a)

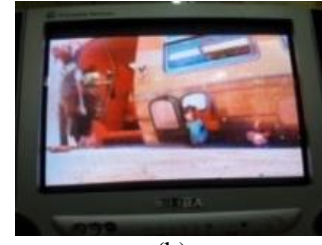

(b)
Gambar 11. Hasil perbandingan antena default dan antena bowtie di jarak $5 \mathrm{~m}$ pada kondisi LOS (a) antena default (b) antena bowtie

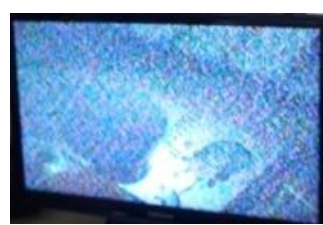

(a)

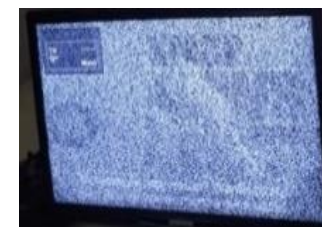

(b)
Gambar 12. Hasil perbandingan antena default dan antena bowtie di jarak $30 \mathrm{~m}$ pada kondisi LOS (a) antena default (b) antena bowtie

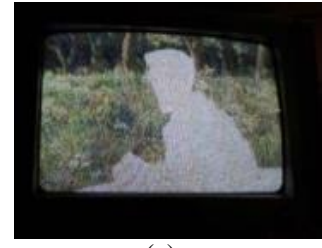

(a)

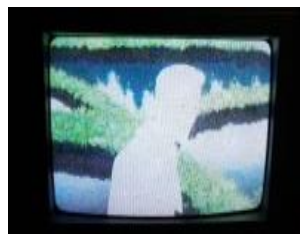

(b)
Gambar 13. Hasil perbandingan antena default dan antena bowtie di jarak 5 m pada kondisi NLOS (a) antena default (b) antena bowtie



(a)

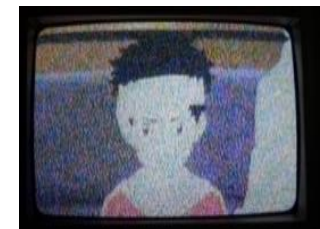

(b)
Gambar 14. Hasil perbandingan antena default dan antena bowtie di jarak $8 \mathrm{~m}$ pada kondisi NLOS (a) antena default (b) antena bowtie

2) Hasil Kualitas Sinyal

Pengujian kualitas sinyal didapatkan hasilnya dari pengukuran menggunakan SDR dan software yang digunakan adalah sdrSharp. Dari Gambar 15 dapat dilihat bahwa semakin jauh jarak, semakin menurun pula kekuatan sinyalnya. Hal ini wajar karena terjadinya penurunan sinyal seiring bertambahnya jarak.

Walaupun ada penurunan nilai, namun tiap jarak memiliki hasil field strength yang sesuai dengan standar ditentukan dari Perkominfo No. 31 Tahun 2014 tentang Rencana Induk (Master Plan) frekuensi radio penyelenggaraan telekomunikasi khusus untuk keperluan siaran analog pada pita ultra high frequency yaitu $70 \mathrm{dBuV} / \mathrm{m}$ untuk band $\mathrm{V}$. Untuk pengujian kualitas sinyal pada kondisi NLOS ditunjukkan pada Gambar 16.

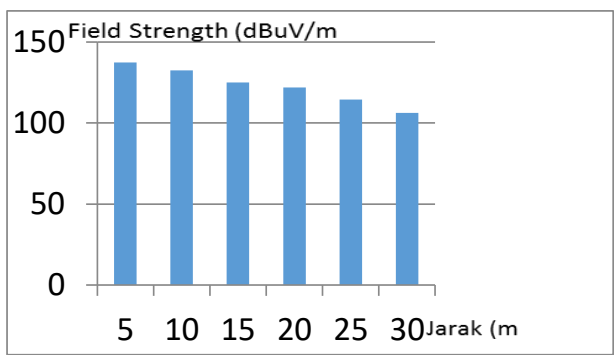

Gambar 15. Hasil field strength antena bowtie pada kondisi LOS

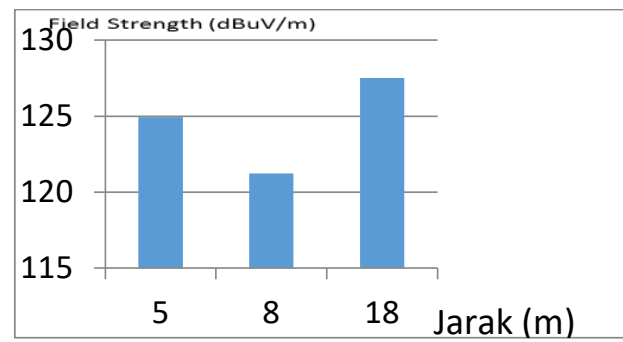

Gambar 16. Hasil field strength antena bowtie pada kondisi NLOS 
Jika dilihat dari grafik di Gambar 16, grafik frekuensi ini fluktuatif dikarenakan perbedaan jenis partisi antara pemancar dan penerima pada masing-masing jarak. Pada jarak $5 \mathrm{~m}$ partisinya adalah gypsum dan kaca, jarak $8 \mathrm{~m}$ memiliki partisi kayu, kaca, dan tembok sedangkan pada jarak $18 \mathrm{~m}$ partisinya adalah kaca, kayu, dan gypsum. Secara umum, nilai dari field strength yang didapat ini memenuhi standar yang telah ditentukan dari Perkominfo No. 31 Tahun 2014 tentang Rencana Induk (Master Plan) frekuensi radio penyelenggaraan telekomunikasi khusus untuk keperluan siaran analog pada pita ultra high frequency yaitu $70 \mathrm{dBuV} / \mathrm{m}$ untuk band $\mathrm{V}$.

Jika dibandingkan dengan penelitian yang telah dilakukan sebelumnya [7] terkait field strength hasilnya sangat berbeda. Field strength yang dilakukan di penelitian sebelumnya mengukur kekuatan sinyal dari salah satu televisi swasta nasional pada wilayah Palembang dan hasil field strength nya adalah di bawah $100 \mathrm{dBuV} / \mathrm{m}$ pada masing-masing daerah di Palembang. Hal tersebut wajar karena pada pengukuran di daerah Palembang daya pemancar dan jarak dari pemancar berbeda, daya pemancar tentunya lebih besar dan jarak antara pemancar dan penerima sangat jauh. Sehingga perbedaan hasil antara penelitian ini yang cakupannya hanya satu tempat dengan penelitian sebelumnya adalah wajar.

\section{IV.PENUTUP}

Berdasarkan data dan analisa tentang parameter antena dan performansi aplikasi antena bowtie, maka dapat disimpulkan bahwa Antena Bowtie pada video sender memiliki frekuensi kerja 655,25 MHz dan nilai return loss $-21,127 \mathrm{~dB}$, VSWR 1,192, pola radiasi bi-directional dan gain-nya adalah $511 \mathrm{~dB}$. Antena bowtie yang telah dibuat ini dapat memancarkan audio dan video hingga jarak $30 \mathrm{~m}$, mampu memancarkan audio dan video dalam kondisi LOS maupun NLOS, memiliki level sinyal atau field strength di atas standar yang ditentukan yaitu $70 \mathrm{~dB} \mu \mathrm{V} / \mathrm{m}$.

\section{REFERENSI}

[1] Triprijooetomo dan M. D. Nandari, "Rancang Bangun Antena Mikrostrip LDPA sebagai Repeater untuk Siaran Televisi”, Jurnal SETRUM, Vol. 5, No.1, 2016.

[2] A. A. Abdou ,et al., "A Matched Bow-Tie Antenna at $433 \mathrm{MHz}$ for Use in Underwater Wireless Sensor Networks", Journal Physics. Vol.450. No.1, 2013

[3] E. H. Hadyan, et al., Perancangan Antena Bowtie sebagai Penerima Siaran Televisi Digital pada Rentang Frekuensi UHF (Ultra High Frequency), TRANSIENT, Vol.4, No.4, 2015.

[4] K. Kavitha dan S. P. Rajan, "Design of Rounded Bowtie Antenna for Indoor Applications", International Journal of Science and Research (IJSR), Vol. 5 Issue 11, 2016.

[5] KOMINFO, Peraturan Menteri Komunikasi dan Informatika Nomor 31 Tahun 2014 tentang rencana induk (master plan) frekuensi radio penyelenggaraan telekomunikasi khusus untuk keperluan siaran analog pada pita ultra high frequency.

[6] T. A. Riza, et al., "Analisis Antena Bowtie pada Frekuensi 500-700 MHz untuk TV Digital di Indonesia”, Jurnal Elektro Telekomunikasi Terapan (JETT), Vol 2, 2015.

[7] R. Susilo, dkk, "Analisa Pengukuran Field Strength pada Service Area Pemancar PT Televisi Transformasi Indonesia (Trans TV) Palembang", Jurnal Desiminasi Teknologi Vol.2,113-118, 2014. 